\title{
The ethics of care and transformational research practices in Aotearoa New Zealand
}

\section{Abstract}

Democratising methodologies often require research partnerships in practice. Research partnerships between indigenous and non-indigenous partners are commonplace, but there is unsatisfactory guidance available to non-indigene researchers about how to approach the relationship in a way that builds solidarity with the aims of the indigenous community. Worse still, non-indigenous researchers may circumvent indigenous communities to avoid causing offense, in effect silencing those voices. In this article, we argue that the ethics of care provides a framework that can guide ethical research practice, because it attends to the political positioning of the people involved, acknowledges inequalities and aims to address these in solidarity with the community. Drawing on our research partnership in Aotearoa New Zealand, we explain how the ethics of care intertwines with Māori values, creating a synergistic and dialogic approach.

Key words

Decolonising methodologies, Māori, ethics of care, participatory methodology

\section{Introduction}

With increased mobility and emphasis on international research, researchers negotiate complex and sometimes extraneous research situations. For many years, researchers concerned about processual situated research ethics have reflected on their research experiences, providing detailed accounts of negotiated difficulties. These reflections are limited because by nature they are specific, and because they partially engage with the broader issues of ethics, politics and privilege in cross cultural, transnational or internationalised contexts. This paper arose from experience of a research partnership between the authors. Tula is second generation Irish from the UK and lived in Aotearoa New Zealand from 2006 - 2015. Amohia is a Māori woman with tribal affiliations to Ngāti Ranginui, Ngai te Rangi and Ngāti Pukenga in the Bay of Plenty and Ngāti Mutunga in Taranaki. 
Where Māori (indigenous peoples of Aotearoa) and Pākehā (non- Māori or settler) researchers work in partnership, there are political, processual and ethical considerations at play, but only limited guidance available for Pākehā about how to manage the relation. We suggest that the ethics of care is a way of thinking about the world (in this case research) that frames an analysis of politics, privilege and power to guide researchers to respond ethically in complex and/or extraneous research circumstances. It provides a critical framework for ethical research raising questions of researcher privilege and power to encourage solidarity with the decolonising aims of Māori communities. We would also argue that these principles are relevant for other research contexts, including other indigenous contexts, where power and privilege feature.

The political context of colonisation is far-reaching and ever-present for indigenous populations, apparent in shortened life expectancy, poorer housing and education outcomes, higher rates of poverty and long-term illnesses, and loss of land and culture. These impacts have been experienced to varying extents across different sites of colonisation (Boulton and Brannelly 2015). Health, poverty and social care are frequent topics for social researchers, that require research approaches that do not echo colonising practices and attitudes or worse still, recolonize. As Linda Tuhiwai Smith recognised

... the term research is inextricably linked to European imperialism and colonialism and is one of the dirtiest words in the indigenous dictionary ... as knowledge is collected, classified and then represented back to the West. The word research stirs up anger, silence and distrust.

(Smith 2005)

So while the processes of colonisation have caused the social issues that require investigation, so too has it tainted the relation between indigenous and settler communities, which may prevent external access to those communities that know how best to find resolutions. For 
Māori, self-determination is essential for exercising knowledge and culture in safe spaces uninterrupted by dominant Pākehā politics. Māori have struggled to assert ownership and control over all aspects of life, research included, as a response to the impacts of colonisation. Turner (2006, p 95) recognised that research participation raises a tension in indigenous communities because it is unclear how indigenous communities' ways of understanding the world ought to be expressed to the dominant culture. An obvious response here is that research is undertaken within indigenous communities by indigenous scholars, and while the capacity for this work is growing, partnerships between indigenous and settler researchers continues. Not only is increased capacity for Maori research essential, partnership research that brings together conflicting and non-consensual perspectives is also needed to enable dialogic engagement and ultimately present opportunities for action for change (Barnes et al 2015). Researchers, therefore, need to be open to acknowledging and recognising various forms of knowledge that are made available to them. They also need to recognise that some knowledge remains uncollectable by (non-indigenous) researchers, protected intellectual property that is private to communities.

That researchers grapple with personal and theoretical assumptions while making decisions in the field is well known (Edwards and Ribbens 1998). Researchers are expected to operate within an expert frame of reference, such as health and social care service provision, theory and policy, however, when academics study populations in social, political and cultural contexts unknown to them there is a need for a diversification of their frame of reference (Koobak and Marling 2014) to avoid analysis from the point of a fixed Western and colonising gaze. Forms of recolonising practices are enacted unknowingly by proponents, who are in 'sanctioned ignorance' (Spivak 1988 p287), a characteristic of the power 'between the centre and the peripheries’ (Koobak and Marling 2014 p6). Bell (2008) suggests that the 
purpose of ethics is to interrupt the centring of the dominant, and therefore diminish the colonial act of mastery. Unsure about how not to practice in a way that suggests recolonization, one problematic response that non-indigenous researchers have adopted is to omit Māori from research that includes the general population altogether. Tolich (2002) explained 'Pākehā paralysis' where settler researchers avoided working with Māori in research studies to sidestep the difficulties of negotiating inclusion, an approach that was problematically sustained through a lack of challenge by Aotearoa institutions such as ethics committees.

For Māori, inclusion of the community in guiding research is essential, and this approach overlaps with feminist participatory approaches. Both feminist and indigenous research seek immediate and direct benefit to the researched community (Smith 1999 p166), and both developed from the need for ownership and control of research, by researchers embedded within communities. Despite there being some overlap in feminist participatory approaches and Māori approaches to research, there are also significant differences. Māori approaches to research are borne of the culture of Māori, guided by a Māori worldview and hence Māori values, and governed by tikanga (correct procedure or custom), and this is how any relation would occur within Māori life.

\section{Ethics of care}

We suggest that one approach that is overlooked as a potential framework and guide for decolonising research is the feminist ethics of care as proposed by Tronto (1993 and 2013), and suspect that is has been overlooked as the criticisms levelled at the ethics of care tend to see it as a single theoretical perspective, rather than a feminist philosophy. For example, as in Hankivsky's (2014) misguided analysis of the ethics of care as a single perspective that 'care ethics is not an inherently intersectional perspective' (Hankivsky 2014 p252), rather than a feminist philosophy that hosts diverse theory. Another critique tends to focus on the 
normativity of the ethics of care, that 'in practically all contexts of behaviour we are confronted with questions of judgement and responsibility...the central categories of a good ethics' (Sevenhuijsen 1998 p37). This is a challenge to reflect on, examine and challenge social practices as normative spaces, to ask who and what constructs and constrains those spaces. As such, feminist ethics of care enables explicit consideration of issues of politics, privilege and ethics, calling for recognition of inequality, and responsibility for action in solidarity with the people affected.

The ethics of care is a political theory and a feminist philosophy that draws out the connection between morality and politics, and calls for political recognition of care. It is a burgeoning area of interest in many disciplines (Barnes et al 2015), and research methodology (Ward and Gahagan 2010). Tronto’s (1993 and 2013) ethics of care is a political argument for care alongside moral aspects of caring practices (attentiveness, responsibility, competence, responsiveness and solidarity). This two-pronged approach enables on one hand, a political, complex and situated examination of inequality and marginalisation, and on the other hand the integrity of care is a set of moral elements to guide inclusive practice.

Recent developments in the ethics of care (Tronto 2013, Barnes 2012) have called for a reconnect with the political feminist concerns of care ethics such as equality, justice and the avoidance of domination (Barnes et al, 2015). In this section, we use the ethics of care to surface concerns about privilege, marginalisation and oppression, and refer to indigenous scholars for guidance to supplement the moral aspects of the integrity of care. Resonances between the ethics of care and Maori research are present in the emphasis on research as 
political action, breaking down the barriers of lay and expert knowledge and the importance of the relation of those involved.

As Hage (in Mookherjee et al 2009 p354) points out, the interrelation between humans is enjoyed best as a 'co-propelling relation' that forms of dominance serve to negate. Hage notes that indigenous people live in a hostile environment where vulnerability is the norm. We would add that constant vigilance is required to address that hostility, in an environment where dominant privilege is ignored. Bozalek (2015, p83) defines privilege as 'unearned social and structural advantages which benefit dominant groups or those who occupy positions of power in society at the expense of marginalised groups.' Privilege has an unmarked status, is invisible and normalised in society; it makes people feel at home. Privilege accrued from colonisation is conveniently forgotten. Tronto (2013 p127) states

The problem also is that those who have benefitted from past injustice have a great incentive to forget that fact, whether they perpetrated injustice or were simply bystanders who benefitted from the unjust acts of others, and those who have been so harmed cannot grasp how the world can go forward simply by ignoring or burying the past.

Indigenous people counter continuing domination through social and political action, therefore specific recognition of indigenous people is crucial - they are not another population within society, but a group who deserve exceptional attention. Young (2011) suggests that 'Blindness to difference perpetuates cultural imperialism by allowing norms expressing the point of view and experience of privileged groups to appear neutral and universal’ (p165). Bozalek (2015) suggests Young’s social connection model of responsibility to tackle privileged irresponsibility (i.e. bringing all parties together to explicitly consider collective action) as the way forward to address injustice, achieved through relational care in different contexts, including research relationships. 
There are many ways of knowing, and many ways of producing knowledge. Barnes’ (2012 p 147) discussion of deliberation with care recognises the potential for the ethics of care to inform and influence participatory modes of governance, and can be applied to the aim of supporting Māori self-determination through explicit recognition of different forms of knowledge and forms of producing knowledge. Identifying how certain knowledges are privileged in deliberation, Barnes draws on Young's inclusion of 'greeting, rhetoric and storytelling' (p157) to enable and recognise diverse contributions to achieve careful deliberation. Getting the relation off to a good start is particularly important to Māori. Te Awekotuku (in Smith 1999, p 120) refers to the position Māori afford to the concept of manaaki ki ngā tāngata (hosting or taking care of the people). For Māori, the ceremony of pōwhiri marks the beginning of a process by which new relationships are established (Mead 2003). Formalised and steeped in protocol, the pōwhiri acknowledges ancestral connections and a new future for participants (Brannelly, Boulton and Te Hiini 2011). McClintock, Tauroa and Mellsop (2012) suggested a pōwhiri process of engagement in health practice settings. Te Awekotuku (in Smith 1999, p 120) suggests that in to get the best from a research relationship, particularly when that relationship is new, meetings must be kanohi ki te kanohi (communicating face to face), where tītiro, whakarongo and kōrero (looking, listening and only then, speaking) is valued.

Researchers are encouraged to take care when entering a new community or establishing a new relationship (kia tūpato). This advice is not given due to any harm that may befall the researcher, but rather so that the researcher does not visit any unintended harm upon the community. Hence, in learning about a community, in truly being attentive, listening to the voices of community, and the knowledge they offer, researchers may well find that a distinctly different set of questions require investigation than those originally theorised, or a 
different set of practices are required. In indigenous cultures, many people may expect to be present at an interview, particularly if it is about people within their community. Researchers may need to consider hosting multiple participants where they wish to contribute, such as an extended family coming together to discuss the wellbeing of a young person. Research is often bound to a singular experience, or draws on a single aspect of a person's identity, and in research that examines the experiences of Māori, there is a call for people to filter their experience primarily through this lens. However, although experiences may be contextualised through colonisation, they should not be required to be presented as such, but as part of everyday life influenced by the many social processes and identities held by participants.

Sensitivity to the ownership and protection of intellectual and tribal property (that has been continually threatened for indigenous people since colonisation) is necessary to ensure that conceptualisations of knowledge and processes are properly attributed and protected. Te Awekōtuku notes that Māori value an approach that demonstrates, amongst others, aroha ki ngā tāngata (respecting people), kaua e takahia te mana o te tangata (maintaining the integrity of the person), and kia māhaki (not flaunting your own knowledge). This humility may be in direct contention with academic norms that value direct challenge and arguments that compete for the final word.

Sevenhuijsen (1998) reminds us of the radically different image of human nature that the ethics of care proposes, 'a moral agent who is embedded in concrete relationships with other people and who acquires an individual moral identity through the interactive patterns of behaviour, perception and interpretations' (p 55). We are shaped by our openness to, and interactions with others to question and challenge apparent norms and privilege, 'a processual self, a self that is continually in the process of being formed; moral identity is continually 
being developed and revised through this process' (Sevenhuijsen 1998 p56). While we are open to question and challenge, and to learning, it should be noted that epistemological differences may not be overcome. The possibility of the 'myriad of dynamics' (Hart et al 2016) that may reinforce colonisation make it necessary to recognise that the epistemological positioning of the research and researchers, their social reality, influencing the ethical framing of the research questions and approach (Edwards and Mauthner, 2012) are fundamentally different. Such differences in worldviews must be recognised. Being attentive while accepting that there are parts of the other that cannot be known enables understanding (Edwards and Mauthner 2012). This ‘asymmetrical reciprocity’ (Young 2011) calls for a more collective approach to make sense of the world together (Tronto 2013).

In summary, and referring to Tronto's (2013) integrity of care, attention is required to the role of privilege in terms of the positioning and marginalisation of the people involved in the research relationship and the gains from the research. To offset privilege, responsibility remains with researchers to take action that repays the community, which may or may not be part of the research process, and could draw on resources that researchers have access to that the community they are involved with do not. Researchers must take responsibility for the protection of indigenous intellectual property with direction required from the community about what can be shared and how it to acknowledged it. Sevenhuijsen alerts us to the competent moral actor, who is open and available to learn and challenge themselves. People involved in research with indigenous partners may want to develop their understanding of that culture, for example to learn te reo Māori (Māori language) to deepen understanding and participation in Māori protocols such as pōwhiri (Torrie et al 2015). The responsiveness of the community is required at every level of the research process, as is common in other 
participatory practices. Solidarity is required to ensure that the research attends to the project of decolonisation as defined and actioned by indigenous communities.

\section{Guidance available for indigenous - non-indigenous partnerships}

Currently, advice that is available to Pākehā researchers tends to omit explicit reference to the need for research that has solidarity with the aims of decolonising research. For example, New Zealand Health Research Council (2010) guidance reads as though participatory methods are adequate, falling short of requiring researchers to understand their actions in the context of colonising practices. Nowhere in this document is decolonising methodologies discussed. Echoing participatory methodology, it is suggested that to work with Māori communities, researchers should include consultation about the research question and design, methods for including the community and working with the community throughout the project to include dissemination. They also pose the question whether the project could be led by Māori researchers.

Other forms of guidance come in easy reference guides for non-indigenous researchers, such as over simplified codification of the principles of the Aotearoa New Zealand Treaty of Waitangi - participation, protection and partnership (for more information see www.teara.govt.nz/en), or OCAP - ownership, control, access and possession described in First Nations research in Canada (Grattan and O’Donnell 2011). Assuming that these principles have a common meaning (or are even translatable concepts) for indigenous and non-indigenous people is problematic, and the concepts must be defined by indigenous people to have meaning.

Meanwhile, the literature tends to focus on the practical issues of involvement, especially in large territories such as Canada (Gratton and O’Donnell 2011, Caretta and Riaño 2016). The exception to this is Hart, Straka and Rowe (2016) who examine the context of an indigene- 
settler research partnership of Cree elder perspectives on ageing in Canada. The key proponents of decolonising practice are outlined and reflected on by the individual researchers and include confronting colonising practice, commitment to indigenous values, centrality of relationships, creating positive change for indigenous people and that indigenous knowledge is central. Behind these concepts sit the onus on indigenous researchers to host the settler researcher, including facilitating their learning and vouching for them in their communities. Likewise, the settler researcher had a responsibility to acquire and share knowledge about processes and the political situation of the Cree people, as well as adopting an openness as a novice to learn from the community. This discussion paper is helpful to people negotiating similar circumstances.

Fredericks (2010), an aboriginal Australian, presents an excellent critique that recognises the ways in which feminist scholars benefit from their work in indigenous communities but that for aboriginal women, involvement often means 'pretty business' for ceremonial purposes ( $p$ 545), and although present, they are not asked for their opinions. Feminist researchers working in indigenous communities have created methodologies, such as de Ishtar's (2005) three methodological principles of grounding in the relationship, bridging indigenous and feminist knowledge, and being passionately involved and immediately useful to the community. de Ishtar lived with Aboriginal women for two years and was involved in every part of the women's lives. Whether this was what the community of Aboriginal women wanted or was in good judgement as a research technique is questioned ${ }^{1}$, and both examples illustrate under or over involvement of aboriginal communities.

\footnotetext{
${ }^{1}$ Thanks to reviewer of earlier version of this paper for this point.
} 
Feminist postcolonial theory has focussed on the reflections of Western academics on the power relations in the field of study to detect and address issues of (m/p)aternalisation and colonisation. Held (2006) identified the anxiety of feminists wishing to effect change in the global South, and the care that is needed to ensure that the actions taken result in more good than harm (p 165), between 'objectifying, patronising and self-congratulatory' action and a responsibility to address the implications of living in the privileged global North (pg 164). Indeed, a failure to intervene is 'construed as a betrayal of one’s feminist responsibility' (Pardy 2012). Schurr and Segebart (2012), feminist geographers working in Latin America, reflected on how the identification of their privilege from the people they intended to research immediately set a relation that required justification. However, the question is why you would not expect this to happen. Much attention has been given to embodied difference from the perspectives of feminist academics who research in contexts such as the global South, but rarely from the positions of those they research. These examples, along with de Ishtar's approach, highlight how the concern to address inequalities in contexts that are foreign to one’s own, lead researchers into 'tricky ground' (Smith 2005) where they find ethically contentious dilemmas abound. In these situations, researchers need to find responses that use privilege in a creative and positive way, and that respect the community.

One final question about research guided by the ethics of care is what are its limitations. Ultimately, if research practice is underpinned by the principles of the ethics of care, this is no guarantee that care will be experienced by the researched. It is clear that care as intended is not care unless it is experienced as such by the people who receive it, in this case the community who is researched. Indeed, colonialism was enacted through a discourse of care (Narayan, 1995) $)^{2}$. Setting out the ethics of care framework as an aim of the project may help

\footnotetext{
${ }^{2}$ This point was very helpfully raised by a reviewer of an earlier version of this paper.
} 
all involved understand the aims of ethical research that responds to the needs of those involved. Ward and Gahagan (2010 p210) used the ethic of care framework to develop joint research projects between university researchers and a voluntary sector organisation, as it provided context-specific ways of understanding and responding to ethical concerns and relational well-being. Broken down into components, the ethics of care loses its strength as a thread that brings theory and practice together, with an aim of social justice. Stating it as an aim to guide and review research practices enables researchers and the community to respond to and create new ways of knowledge production that breaks down the barriers of lay and expert knowledge (Ward and Gahagan 2010).

\section{Conclusion}

Tronto (1993, 6-10) contested three moral boundaries - morality and politics, the moral 'point of view', and public and private life. Morality and politics are not separate but entirely entwined, and Tronto argues that care can serve as the moral value and political achievement of a good society. To achieve justice with indigenous people requires care (Barnes and Brannelly 2008); care as a value and a political achievement questions the morality and the political action that sustains oppression for some groups of people. Asking these questions surfaces a conversation that is currently framed very differently and is only partly addressed in research. We advocate that the ethics of care is used to state research as a political act, which as various intended and unintended consequences that can be negotiated by researchers and participants.

In care ethics, a distant and disinterested moral position is not the best vantage point to make moral observations, favouring situated, contextualised knowledge that is action-orientated. The moral point of view that has been central to colonisation marginalises the worldview, values and priorities of indigenous people. The problem this presents is that this particular 
moral point of view interprets and translates aspects of lives devoid of context and in the absence of meaning, leading in turn to further dominance. If the shift to a situated understanding of indigenous people were to occur, it is unlikely that the outcome would be further trauma. Moral thought leaves moral action to somebody else. As the ethics of care recognises the complex and messy world in which research is situated, so it enables that complexity to be represented, not ignored, so that the interconnectedness of knowledge and experience are foregrounded.

Tronto's third moral boundary is the boundary between public and private life. Part of the role of research is to encourage hidden voices to be heard, informing others around them of the context and conditions of people's lives. There is a research role to translate the experiences of a group into language and cultural norms known by others. The question is about who, and how this translation occurs, and the audience to whom it is made, that require careful judgement. Care ethics suggests that to achieve the good society, people have a moral responsibility to each other (Tronto 1993, Sevenhuijsen 1998), and people with privilege are in a position that enables the mobilisation of political will and action to make change that ameliorates rather than sustains social inequalities (Young 2011). Inertia represents privileged irresponsibility, where the main benefactors of care do not register its value. Care is pivotal to taking responsibility, and taking responsibility is pivotal to action (Walker 2007). Therefore we suggest that when joining with indigenous groups in partnerships, the actions required to create change form part of the research process, whereby activists from the communities can be supported to make those changes.

The ethics of care may help researchers to frame reflective questions, to surface understanding of the political and justice aspects of research that may not be well 
acknowledged. Analysis of research practices may also be strengthened using the framework to unpack and understand how participation was experienced differently with various groups, both for the researchers and the researched. Ethics of care provides a shared language that is accessible to all, and can be used as a guide for discussions to reflect on research experiences and relationships. Finally, when researchers find themselves on 'tricky ground' (Smith 2005) where political, processual and ethical considerations are at play that present occasions for discussion and exchange of ideas, the ethics of care can be used to understand the origins and implications of the issues, and help to transform practices, develop relationships and evolve to achieve the purpose of decolonisation.

\section{Acknowledgements}

Thanks to the anonymous reviewers for their very helpful critique and suggestions on an earlier version of this paper. 


\section{References}

Barnes M (2012) Care in everyday life, Bristol, Policy Press.

Barnes $\mathrm{M}$ and Brannelly T (2008), Achieving care and social justice for people with dementia. Nursing Ethics, 15, (3), 384-395. (doi:10.1177/0969733007088363).

Barnes, M, Brannelly T, Ward L, and Ward N (2015) Ethics of Care, Critical Advances in International Perspective, Bristol, Policy Press.

Bell A (2008) Recognition or Ethics? Cultural Studies,22:6,850 — 869, DOI 10.1080/09502380701702474

Boulton A and Brannelly T (2015) Care ethics and indigenous values: political, tribal and personal, in Barnes, M, Brannelly T, Ward L, and Ward N (2015) Ethics of Care, Critical Advances in International Perspective, Bristol: Policy Press.

Boulton A, Tamehana J and Brannelly T (2013) Whanau-centred health and social service delivery in New Zealand. MAI Review, 2, (1).

Bozalek V (2015) Privilege and responsibility on the South African context in Barnes, M, Brannelly T, Ward L, and Ward N (2015) Ethics of Care, Critical Advances in International Perspective, Bristol: Policy Press.

Brannelly, T., Boulton, A., Te Hiini, A. (2013). A Relationship Between the Ethics of Care and Māori Worldview-The Place of Relationality and Care in Māori Mental Health Service Provision, Ethics and Social Welfare, Vol 7, No 4, pp410-422. DOI:10.1080/17496535.2013.764001

Caretta MA, Riaño Y (2016) Feminist participatory methodologies in geography: creating spaces of inclusion, Qualitative Research, Vol. 16(3) 258-266, DOI: 10.1177/1468794116629575

dé Ishtar Z (2005) Striving for a common language: A white feminist parallel to Indigenous ways of knowing and researching, Women's Studies International Forum 28, 357- 368

Ribbens, J and Edwards, R (eds.) (1998). Feminist Dilemmas in Qualitative Research: Public

Knowledge and Private Lives. London: Sage

Edwards R and Mauthner M (2012) Ethics and Feminist Research, Theory and Practice, in Miller T, Birch M, Mauthner M and Jessop J (eds), Ethics and Qualitative Research, $2^{\text {nd }}$ edition, London, Sage, pp $14-28$.

Fredericks B L (2010) Reempowering ourselves: Australian aboriginal women, Signs: Journal of women and culture in society, 35(3), 546 - 550.

Grattan MF and O’Donnell S (2011), Communication technologies for focus groups with remote communities: a case study of research with First Nations in Canada, Qualitative Research, 11(2) 159175, DOI: $10.1177 / 1468794110394068$

Hankivsky O (2014) Rethinking care ethics: On the promise and potential of an intersectional analysis, American Political Science Review, vol 108, 2, 252264, DOI 10.1017/S0003055414000094

Hart M.A, Straka S and Rowe G (2016) Working Across Contexts: Practical Considerations of Doing Indigenist/Anti-Colonial Research, Qualitative Inquiry, 1 - 11, DOI: 10.1177/1077800416659084 Health Research Council of New Zealand (2010), Guidelines for Researchers on Health Research involving Māori, version 2, Auckland: Health Research Council.

Held V (2006) The Ethics of Care Personal, Political and Global, New York, Oxford University Press.

Koobak R and Marling R (2014) The decolonial challenge: Framing post-socialist Central and Eastern Europe within transnational feminist studies, European Journal of Women's Studies, DOI:

10.1177/1350506814542882

McClintock K, Tauroa R and Mellsop G (2012), An examination of Child and Adolescent Mental Health Services for Māori ragatahi [youth], International Journal of Adolescence and Youth, DOI: 10.1080/02673843.2012.692658

Mead H M (2003) Tikanga Maori, Living by Maori Values, Wellington: Huia.

Mookherjee N, Rapport N, Josephides L, Hage G, Renier Todd L and Cowlishaw G (2009) The

Ethics of Apology: A Set of Commentaries, Critique of Anthropology, 29, 345, DOI

10.1177/0308275X09336703 
Narayan U. (1995) 'Colonialism and its others: considerations on rights and care discourses', Hypatia, 10: 133-40.

New Zealand Health Research Council (2010) Guidelines for Researchers on Health Research Involving Mãori, Auckland, Health Research Council.

Pardy M (2012), 'Responsible Judgement: Forced Marriage, Culture and Feminist Responsibility', in Hage G and Eckersley R (eds), Responsibility, Melbourne, Melbourne University Press.

Schurr C and Segebart D (2012) Engaging with feminist postcolonial concerns through participatory action research and intersectionality, Geographica Helvetica, 67, 147-154, 2012, doi:10.5194/gh-67$147-2012$

Sevenhuijsen S (1998), Citizenship and the Ethic of Care Feminist Considerations on Justice, Morality and Politics, London, Routledge.

Smith L.T. (1999) Decolonising methodologies, research and indigenous communities, London: Zed books.

Smith L.T. (2005) On Tricky Ground, Researching the Native in the Age of Uncertainty, in Denzin, N. K., \& Lincoln, Y. S. (Eds). The SAGE handbook of qualitative research. Thousand Oaks: Sage Publications.

Spivak GC (1988) Can the subaltern speak? In: Nelson C and Grossberg L (eds) Marxism and the Interpretation of Culture. London: Macmillan, pp. 271-313.

Te Ara http://www.teara.govt.nz/en/treaty-of-waitangi Accessed 31.08.2016

Tolich M (2002) Pākehā paralysis: Cultural safety for those researching the general population of Aotearoa, Social Policy Journal of New Zealand, 19, 164 - 178.

Torrie R Dalgety M, Peace R, Roorda M and Bailey R (2015) Finding our way: Cultural competence and Pākehā evaluators, Evaluation Matters - He Take Tō Te Aromatawai, 1:2015 47 - 81, doi:

10.18296/em.0004

Tronto J.C (1993) Moral Boundaries, a political argument for an ethic of care, New York University Press, New York.

Tronto J.C (2013) Caring Democracy, New York University Press, New York

Turner D (2006) This is not a peace pipe, Towards a Critical Indigenous Philosophy, University of Toronto Press, Toronto.

United Nations (2009) State of the World's Indigenous Peoples. Economic and social affairs, United Nations: New York.

Walker MU (2007), Moral Understandings, A feminist study in ethics, Second edition, New York, Oxford University Press.

Ward L., Gahagan B, (2010) Crossing the Divide between Theory and Practice: Research and an Ethic of Care, Ethics and Social Welfare, 4:2, 210-216, DOI: 10.1080/17496535.2010.484264 Young I.M, (2011) Justice and the politics of difference, Princeton, Princeton University Press. 